\title{
OS SONÂMBULOS QUE LEVARAM A EUROPA AO ABISMO
}

DOI: http://dx.doi.org/10.15448/2178-3748.2015.1.20697

Christian Satto

Professor Pesquisador - Scola Normale Superiori (SNS) de Pisa

E-mail: christian.satto@sns.it

CLARK, Christopher. Os sonâmbulos: como eclodiu a Primeira Guerra Mundial de Christopher Clark (São Paulo: Companhia das Letras, 2014).

A Grande Guerra teve um impacto profundo sobre a sociedade contemporânea, marcando o final de todos os efeitos do "longo século XIX". O conflito representou o crepúsculo da supremacia mundial da Europa e de uma civilização convencida de que fosse possível guiar a humanidade, através do conhecimento e da razão, em direção a um futuro de progresso e de pacífica convivência entre as grandes potências continentais. Isso não excluía a possibilidade de que a projeção colonial delas não comportasse conflitos ativos entre elas. O importante era impedir uma guerra que pudesse levar a uma desestabilização dos equilíbrios entre as potências, como ocorrera anteriormente, em 1870 - este era o objetivo da diplomacia da época. No final, a guerra, aliás, a "Grande Guerra", que todos queriam evitar, mas que na realidade se preparavam para enfrentar, eclodiu, e, após cinquenta e três longos meses de devastação, mudou a sensibilidade dos contemporâneos, forçados a confrontar-se com uma realidade tanto nova quanto terrível, que deixou vestígios profundos em todos aqueles que foram envolvidos. Também por este motivo, a pesquisa das causas de tudo isso, como se pode entender, atraiu os historiadores desde o primeiro momento.

A historiografia sobre as origens da grande guerra, de fato, dispõe de um mare magnum de milhares de contribuições, dentre artigos e livros publicados já a partir dos anos nos quais se desenvolveu o conflito.

Entre os trabalhos emblemáticos sobre o nunca adormecido interesse pelos eventos que levaram ao conflito, salienta-se aquele do historiador australiano, atualmente professor em Cambridge, Christopher Clark The Sleepwalkers: How Europe

${ }^{1}$ Resenha traduzida por Antonio de Ruggiero e Leonardo de Oliveira Conedera.

Oficina do Historiador, Porto Alegre, EDIPUCRS, v. 8, n. 1, jan./jun. 2015, p.81-89. 
Went to War in $1914 .^{2}$ A grande repercussão dessa obra deveu-se não apenas ao grande número de resenhas que recebeu nas páginas de revistas especializadas e nos maiores jornais internacionais, mas também graças à rapidez da sua difusão no mundo dos estudiosos e do grande público, através das inúmeras traduções de que foi objeto. ${ }^{3} \mathrm{O}$ título, The Sleepwalkers, "os sonâmbulos", como ele mesmo explica no final do livro, se refere àqueles estadistas europeus que, em 1914, estavam "aparentemente atentos, mas não em condições de ver, atormentados pelos pesadelos, mas cegos frente à realidade do horror que estavam para espalhar no mundo" (p. 606). Todos aqueles homens tinham uma visão da política na qual se sentiam agredidos, e, pensando nos movimentos para responder aos ataques, justificando entre as opções possíveis também uma guerra preventiva, intendida como defesa desesperada, antes que o front adversário se fortalecesse demais para ser vencido, não percebiam que estavam colocando as bases para a destruição da Europa.

É preciso dizer que Clark não se preocupa em reconstruir tanto o porquê da guerra, pergunta à qual, apesar de um século de pesquisas, não se conseguiu responder plenamente, sendo difícil encontrar um motivo bem preciso dentro da densa textura de causas que estão por detrás da principal crise internacional. "A questão do porquê escreve Clark na sua "Introdução" - nos induz a pesquisar as causas remotas e atribuídas a categorias precisas: imperialismo, nacionalismo, armamentos, alianças, alta finança, senso de honra nacional, dinâmicas de mobilização. Perguntar pelo porquê traz certa clareza analítica, mas gera ao mesmo tempo, um efeito distorcido, enquanto cria a ilusão da existência de mecanismos causais que operam uma pressão constante e crescente; os fatores se acumulam um sobre o outro, desvalorizando os eventos, e os atores políticos tornam-se simples executores de forças presentes há tempos, e fora do controle deles" (p. XVIII). Esses são os motivos pelos quais Clark prefere o como ao porquê, mesmo que, no livro, os dois planos frequentemente se entrelacem, e seja difícil mantê-los separados. Falando do porquê, segundo Clark, se arrisca a ser excessivamente influenciado por aquilo que aconteceu posteriormente. Essa distinção, que da

\footnotetext{
${ }^{2}$ London: Allen Lane, 2012. Nas citações da presente resenha, as indicações entre parênteses se referem à edição italiana.

${ }^{3}$ Les Somnambules: Été 1914: Comment l'Europe a marché vers la guerre. Paris: Flammarion, 2013; Die Schlafwandler: Wie Europa in den Ersten Weltkrieg zog. München: Deutsche Verlags-Anstalt, 2013; I sonnambuli. Come l'Europa arrivò alla grande guerra. Roma-Bari: Laterza, 2013; Sonámbulos: Cómo Europa fue a la guerra en 1914. Barcelona: Galaxia Gutenberg, 2014; Os Sonâmbulos. Como a Europa Entrou em Guerra em 1914. Lisboa: Relógio D'Água, 2014.
}

Oficina do Historiador, Porto Alegre, EDIPUCRS, v. 8, n. 1, jan./jun. 2015, p.81-89. 
perspectiva da narração se revela eficaz, parece um pouco artificiosa: é inevitável que mesmo a pesquisa do como afete os debates e as interpretações surgidas após a guerra.

A questão do porquê, além disso, segundo Clark, implica, desde o início, aquela da culpa, e, portanto, de quanto foi decidido nos tratados posteriores ao conflito. A culpa da Alemanha, como sabemos, foi fixada pelo artigo 231 do tratado de Versalhes, que declarava: "Os Aliados e os Governos Associados afirmam, e a Alemanha aceita, a responsabilidade da Alemanha e dos seus aliados, por ter causado todas as perdas e os danos que os Aliados e os Governos Associados e os seus cidadãos tiveram em consequência da guerra a eles imposta pela agressão da Alemanha e dos seus aliados". Os vencedores, assim, decretaram que o Reich forjado por Bismarck foi o responsável único pela guerra (os seus principais aliados, a Áustria-Hungria e o Império Otomano foram desfeitos). $\mathrm{O}$ art. 231 colocou preto no branco a questão da culpa alemã, cuja organização historiográfica mais estruturada se atribui a Fritz Fischer. ${ }^{4}$

Segundo ele, de fato, a guerra não aconteceu por acaso, mas sim foi o produto de uma escolha consciente operada pelos grupos dirigentes alemães para romper o isolamento europeu da Alemanha, já pressionada por dois lados, a fim de lançar as bases para aquele ímpeto mundial, objetivo do período Guilhermino. Opositor desta tese foi outro historiador alemão, Gerhard Ritter, que escreveu uma obra em três volumes sobre a influência do militarismo na Alemanha, recusando a ideia fischeriana do planejamento consciente da guerra. ${ }^{5}$ Clark não nega o conservadorismo, o militarismo e o nacionalismo que caracterizavam a classe dirigente do período Guilhermino. Contudo, procura inseri-los em um contexto mais amplo, onde também outros atores importantes exerceram papel de protagonistas. Em uma passagem importante da "Conclusão", Clark afirma que "a eclosão da guerra de 1914 não é um episódio de um drama de Agatha Christie, no final do qual se descobre o culpado com uma arma na mão, ao lado de um cadáver. Nesta história, cada um dos personagens principais tem em mão um revólver. Se olhamos por esta perspectiva, a eclosão da guerra foi uma tragédia, não um delito com um único culpado. Reconhecer isso não significa minimizar aquelas obsessões de molde beligerante e imperialista dos políticos austríacos e alemãs [...]. Mas os alemães não eram os únicos imperialistas, e não eram os únicos a serem vítimas de obsessões

\footnotetext{
${ }^{4}$ Fischer, Fritz. Griff nach der Weltmacht. Die Kriegszielpolitik des kaiserlichen Deutschland 1914-1918. Düsseldorf: Droste, 1961.

${ }^{5}$ Ritter, Gerhard. Staatskunst und Kriegshandwerk. Das Problem des „Militarismus“ in Deutschland, IIII. München: Oldenbourg, 1954-1964.
}

Oficina do Historiador, Porto Alegre, EDIPUCRS, v. 8, n. 1, jan./jun. 2015, p.81-89. 
paranoicas” (p. 604-605). Daí a necessidade de uma análise mais ampla, no máximo possível imune de preconceitos de culpas.

Aquilo que, de fato, distingue Os Sonâmbulos das demais publicações recentes sobre as origens da guerra, as quais, também reconstruindo um quadro complicado e conflituoso das relações internacionais da época, tendem a considerar o papel da Alemanha como preponderante no processo que levou a conflagração europeia ${ }^{6}$, é sua tentativa de suavizar e rever, mas sem subverter, o assunto da culpa alemã. Por isso, se introduzem novos aspectos de reflexão, como aqueles que levam a considerar, mais do que foi feito até hoje, o importante papel da Rússia. O Império czarista, de fato, depois da frustrante derrota contra o Japão na guerra de 1904-1905, com a consequente revolução interna, e o acordo com a Inglaterra para delimitar as respectivas esferas de influência no Oriente (1907), permaneceu com um só palco para suas iniciativas na política exterior: os Bálcãs. Revendo o equilíbrio de potência da zona através da aliada Sérvia, São Petersburgo percebia a possibilidade de alcançar finalmente o Mediterrâneo, sem passar pelos estreitos pertencentes aos turcos.

Para reconstruir o como se chegou ao conflito, Clark recorre a um quadro narrativo rico de detalhes, e, especialmente nas fases que sucederam ao atentado de Sarajevo, analisado quase minuto a minuto, evidenciando as medidas e as contramedidas das diversas chancelarias europeias. A essa rica e meticulosa reconstrução dos eventos posteriores ao dramático atentado de 28 junho de 1914, é dedicada a terceira parte do livro. Aqui Clark confirma como ninguém queria, na realidade, a guerra. Muitos dirigentes políticos estavam ainda em férias, em julho. $\mathrm{O}$ fato de que as crises precedentes, como as "marroquinas" (1905 e 1911) e a anexação da Bósnia-Herzegovina (1908), tivessem sido resolvidas sem recorrer a uma guerra, constituía um exemplo positivo de como a diplomacia conseguiria, no final, a neutralizar as situações mais incendiárias. Se pensava que também a crise de julho pudesse terminar exatamente como as anteriores.

$\mathrm{O}$ antagonismo austro-servo é o objeto da primeira das três partes na qual se estrutura o livro. Nos primeiros dois capítulos, de fato, os protagonistas são os

\footnotetext{
${ }^{6}$ O ano de 1914 está sendo, nestes últimos anos, foco de vários estudos. Limito-me, por isso, a lembrar alguns deles: MacMillan, M. The War That Ended Peace: The Road to 1914. London: Profile Books, 2013; Hastings, M. Catastrophe 1914: Europe Goes to War. London: William Collins, 2013. McMeekin, S. The Russian Origins of the First World War. Cambridge (Mass.): Harvard University Press, 2011 (o título sugere a importância deste trabalho).
}

Oficina do Historiador, Porto Alegre, EDIPUCRS, v. 8, n. 1, jan./jun. 2015, p.81-89. 
"fantasmas sérvios" e "o império sem qualidade" do qual se destacam as características gerais (grau de desenvolvimento social-econômico-cultural, sistema de governo, relações internacionais, etc.). No final das contas, a tensão austro-servia foi a origem daquilo que, de mobilização em mobilização, conduziu aos chamados "canhões de agosto", para citar o famoso ensaio de Barbara Tuchman. ${ }^{7}$

Clark, de fato, inicia sua narração dos eventos que originaram a crise de julho de 1914 a partir dos Bálcãs, mas não do assassinato de Francisco Ferdinando, em 28 de junho, em Sarajevo, nem das guerras que desestabilizaram irreparavelmente a área entre 1912 e 1913, mas pelos fatos sangrentos de 11 de junho de 1903, quando, em Belgrado, um grupo de oficiais infiéis trucidou barbaramente o rei Alexandre Obrenović e sua esposa, a rainha Draga. Aquele terrível gesto marcou uma reviravolta na inserção internacional da Sérvia. Até então, de fato, os Obrenović a mantiveram ligada ao potente vizinho austro-húngaro. Entre os militares golpistas, destacava-se a figura de Dragutin Dmitrijević, mais conhecido como Apis, componente do estado-maior, que dirigirá, nos anos subsequentes, os serviços secretos sérvios, e a "mão negra", a sociedade secreta nacionalista e terrorista implicada no homicídio de Francisco Ferdinando da Áustria. A nova dinastia, os Karadjordjévic, com Pedro I, recebendo a orientação fortemente nacionalista dos ambientes militares que o colocaram no trono, inaugurou uma política fortemente reivindicativa dos direitos da nação sérvia e do pan-eslavismo, aproximando-se da grande potência que era a porta-bandeira dessa ideia: a Rússia de Nicola II.

A Península balcânica, então, vem representada como cruzamento estratégico atravessado por tramas entre nacionalismos agressivos em expansão, como aquele sérvio, e choques de hegemonia entre as grandes potências, que, direta ou indiretamente, possuíam interesses sobre o território. Por esse motivo, também a Áustria-Hungria, aquela complexa miscelânea de nacionalidades diversas sobre as quais reinava o velho Francisco José, é largamente analisada, partindo do pressuposto de que a monarquia habsburga não era um gigante moribundo, mas um ativo protagonista das relações internacionais, disposto a reafirmar o próprio papel na Europa. A Áustria-Hungria, em linha com os estudos de Samuel R. Williamson, não é vista segundo os clássicos estereótipos da "prisão" dos povos, mantidos em uma espécie de equilibrado

${ }^{7}$ Cf. Tuchman, Barbara. The guns of August. New York: MacMillan, 1962.

Oficina do Historiador, Porto Alegre, EDIPUCRS, v. 8, n. 1, jan./jun. 2015, p.81-89. 
descontentamento, através de um governo despótico e complicado. Todavia, talvez, no texto conviria sublinhar de maneira mais forte que ao nacionalismo sérvio os dirigentes austro-húngaros opunham os seus nacionalismos, em particular aqueles ligados às duas etnias dominantes da monarquia: os alemães e os magiares, que, frente aos sérvios, tinham um comportamento oposto, embora fossem unidos pela profunda aversão pelo Estado sérvio. Esquematicamente, se pode dizer que os austríacos também estavam dispostos a aniquilar e se anexar à Sérvia; os húngaros não, pois temiam um aumento numérico de súditos eslavos na monarquia, o que colocaria em dificuldade sua posição de exclusivo domínio político nas terras da Coroa de Santo Estefan. ${ }^{8}$

$\mathrm{Na}$ segunda parte, ao contrário, Clark propõe quatro interrogações, na forma de capítulos específicos: porque a Europa se polarizou em dois blocos? Quem decidia a política externa nos Estados europeus de então? Por que a centralidade dos Bálcãs? Havia outros perigos de guerra? A resposta a esta última pergunta relaciona-se às tensões criadas pelas guerras balcânicas (1912-1313), que levaram (pela primeira vez, no outono de 1913) a Áustria a enviar um duro ultimato à Sérvia, a fim de que ela deixasse o território da recém-formada Albânia. Sobre a centralidade dos Bálcãs, farei algumas considerações logo a seguir.

Muito interessantes são as primeiras duas interrogações, através das quais Clark demonstra que as duas grandes alianças europeias, a Tríplice e a Entente, não eram blocos bem definidos. Pelo contrário, se mostravam repletos de problemas, que somente os eventos de julho-agosto de 1914 concertaram. Enfim, o autor delineia a grande diferença entre os governos de hoje e aqueles daquela época, na qual poucas pessoas decidiam. Contudo, apesar da restrição da esfera pública e da classe dirigente, o Soberano, ou, no caso francês, o Presidente da República, não tinha, na realidade, todo o poder que normalmente atribuímos a ele, mas deveria gerir um sistema de vozes divergentes, difíceis de dialogarem, onde um simples embaixador poderia ter um peso maior que o ministro das relações exteriores. Este é um dado muito importante a se destacar. "Esse caos de vozes em competição entre eles - frisa Clark - é de importância crucial para compreender as agitações periódicas do sistema europeu nos últimos anos anteriores à guerra, e nos ajuda também a explicar por quais motivos a crise de julho de 1914 tornou-se a mais complexa e opaca crise política dos tempos modernos" (p. 184-

${ }^{8}$ Cf. Bled, J. P. L'agonie d'une monarchie. Autriche-Hongrie 1914-1920. Paris: Tallandier, 2014.

Oficina do Historiador, Porto Alegre, EDIPUCRS, v. 8, n. 1, jan./jun. 2015, p.81-89. 
185).

Interessantes, enfim, as diversas imagens que emergem das páginas de Clark: Guilherme II, a quem dedicou também uma biografia ${ }^{9}$; Francisco José e o seu herdeiro Francisco Ferdinando; o czar Nicolau II; o presidente Poincaré. Sem esquecer outros, como o chanceler alemão Bethmann-Hollweg, os ministros exteriores austro-húngaros Aehrenthal e Berchtold, o primeiro-ministro húngaro Tisza, o ministro do exterior russo Sazonov, os generais Moltke, Conrad, Joffre, respectivamente chefes do estado-maior alemão, austro-húngaro e francês; e tantos outros protagonistas importantes no desenrolar da crise que aqui não é possível elencar. Acredito que seja uma escolha positiva dar importância às biografias: sendo um mundo político fortemente baseado sobre as relações pessoais, no caso dos monarcas também conhecidos, é justo apresentar e esboçar a personalidade dos homens chamados a participar dos processos decisivos dos governos que, como dito, eram muito diferentes daqueles a que estamos habituados hoje.

Uma consideração: a Alemanha, a Áustria-Hungria, a França, a Inglaterra, a Rússia e, naturalmente, a Sérvia encontram grande espaço no livro. Pouco interesse, no entanto, suscita a Itália. Não quero propor o cansativo e improdutivo debate se a Itália deva ser considerada a sexta grande potência europeia, ou a primeira das potências médias continentais. O fato é que ela pertencia ao bloco austro-alemão, sendo parte da Tríplice Aliança. Um acordo nunca muito apreciado pela opinião pública italiana, porque previa uma aliança com a Áustria-Hungria, o inimigo histórico do processo de unificação, que dominava ainda as assim chamadas "terras irredentas", simbolizadas pelas cidades de Trento e Trieste. Porque esta escolha de aliar-se à Áustria-Hungria e à Alemanha realizada pelos homens do governo italiano daquele período?

A classe política daquele tempo desenvolveu a convicção de que a Itália era de fato isolada. Depois da queda de Napoleão III, a Itália não era mais considerada um Estado "escravizado" à França, e isto foi um bem. Todavia, não conseguiu encontrar uma colocação própria na Europa, agitando-se sempre no dilema de querer tornar-se uma grande potência, sem nunca conseguir. Depois de 1876, com a ascensão da esquerda e o grave golpe internacional da ocupação da Tunísia (em 1881) pela mão francesa, era necessário inserir-se de forma estável no contexto europeu. E dos

${ }^{9}$ Clark, C. Kaiser Wilhelm II. London: Longman, 2000.

Oficina do Historiador, Porto Alegre, EDIPUCRS, v. 8, n. 1, jan./jun. 2015, p.81-89. 
sentimentos antifranceses difundidos na Península aproveitou Bismarck, propondo a Tríplice Aliança.

As tentativas, porém, de fazer da Tríplice uma alavanca exclusiva da política externa italiana falharam totalmente: o mais clamoroso foi aquele do primeiro ministro Francesco Crispi, que terminou com uma derrota na África, em 1896. Nem a Alemanha nem a Áustria nunca tiveram a intenção de sustentar a política colonial da Itália: ambas, sobretudo Berlim, sustentaram firmemente a identidade "negativa", e não "ativa", da Tríplice, ou seja, sua natureza de pacto defensivo, operante apenas no caso em que um dos membros fosse atacado por uma outra potência. Não havia, neste quadro, espaço para sustentar a política africana empreendida por Roma, e a dura derrota de Adua demonstrou isso, de forma definitiva. Essa linha dos impérios centrais ditou, por consequência, à Itália a necessidade de abrir a própria política externa, procurando negociações com as outras potências europeias não participantes da Tríplice (acordos com a França, com a Inglaterra, com a Rússia). A guerra ítalo-turca pela Líbia, empreendida por Roma com a concordância de Paris e Londres, foi a consequência desta abertura para as potências da Entente. A Tríplice Aliança, todavia, constituiu ainda o eixo da política externa do Reino italiano.

A chave do governo italiano estava no art. 7 da Aliança: a cada extensão da Áustria-Hungria nos Bálcãs devia corresponder uma compensação para a Itália, compensação consistente, por óbvio, nas chamadas "terras irredentas". A Alemanha, nesta situação, se encontrava no papel difícil de mediador. O discurso era claro há anos, e a Itália o confirmou para a Alemanha e a Áustria, ainda em junho de 1914, antes do atentado. O governo italiano, de fato, julgando já inevitável a união sérviomontenegrina, queria usá-la para alcançar o próprio objetivo. Sua ideia era que a Tríplice, antes de entrar em ação, deveria encontrar no seu interior um acordo, caso contrário, a Itália levaria em consideração a ideia de uma mudança de alianças para impedir um posterior crescimento da influência dos habsburgos nos Bálcãs. A Itália, como todos, perseguia seus interesses nacionais. Então, a partir do momento da crise desencadeada em Sarajevo, seja a Áustria, seja a Alemanha sabiam precisamente qual seria a posição do governo italiano em relação a cada intervenção na Península balcânica, e foi por isso que não avisaram Roma sobre aquilo que Viena estava decidindo.

Confirmando aquela que, creio, já se pode definir como uma tradição

Oficina do Historiador, Porto Alegre, EDIPUCRS, v. 8, n. 1, jan./jun. 2015, p.81-89. 
historiográfica consolidada, também Clark, no seu rico livro, concede pouquíssimo espaço à Itália. Na terceira parte do livro, dedicada especificamente à "crise", a Itália aparece só esporadicamente, e somente para sublinhar as ambiguidades nos confrontos dos Aliados. Escreve algumas palavras a mais Clark sobre a guerra da Líbia, quando ocorreu o primeiro bombardeio aéreo (p. 265-267). Ele, porém, afirma que hoje a guerra ítalo-turca "em grande parte foi esquecida" (p. 267). Fato que não é real, porque foi objeto de pesquisas recentes, como aquela de Nicola Labanca. ${ }^{10}$ Pelo contrário, não é aqui o lugar, mas conviria refletir sobre a circulação internacional da historiografia italiana. Apesar de não ter uma importância semelhante àquela das outras potências, a Itália não era um peão irrelevante do sistema europeu, e esse fato deveria ser aprofundado, quando a intenção é mostrar quão intricado e complexo era o sistema das relações internacionais daquele contexto. Entre outras coisas, um dos trabalhos de referência utilizados por Clark é de um italiano, Luigi Albertini, que foi um protagonista direto daquele evento, quando participou do debate intervencionista, na qualidade de diretor do Corriere della Sera, um dos mais influentes e difundidos jornais da época. ${ }^{11}$

Trata-se, de todas as formas - e as fontes e a bibliografia o demonstram, sem dúvidas - de um estudo conduzido de modo rigoroso e detalhado, talvez em alguns pontos até excessivo em percorrer toda a história das relações entre as grandes potências europeias, entre o início do século XX e a eclosão do conflito. Um livro que tem o mérito de estimular a reflexão sobre um dos eventos decisivos da contemporaneidade. Para quem quer entrar no coração da Europa dos primeiros quinze anos do Novecentos, o livro de Clark se revela interessante e cheio de detalhes úteis. É a partir desse complexo mecanismo de eventos entrelaçados que Clark procura esclarecer o como eclodiu a Grande Guerra, mostrando que cada ator tinha suas razões a serem defendidas no plano internacional. Portanto, nenhum assassino com uma arma, mas um suicídio coletivo em direção ao qual os estadistas europeus encaminharam-se como sonâmbulos.

RESENHA ENVIADA EM: 15/05/2015 ACEITA PARA PUBLICAÇÃO EM: 25/05/2015

\footnotetext{
${ }^{10}$ Cf. Labanca, N. La guerra italiana per la Libia, 1911-1931. Bologna: Il Mulino, 2012.

11 Albertini, L. Le origini della guerra del 1914 (3 vols.). Milano: Bocca, 1942-1943 (nova edição: Gorizia: LEG, 2010-2011 [3 vols.]). A primeira tradução em inglês de Albertini é dos anos 1960: The Origins of the War of 1914 (3 vols.). London: Oxford University Press, 1965.
}

Oficina do Historiador, Porto Alegre, EDIPUCRS, v. 8, n. 1, jan./jun. 2015, p.81-89. 